\title{
Development of Prospective Teachers' Noticing Skills Within Initial Teacher Education
}

\author{
Reyhan Tekin-Sitrava $^{1}$ (D) $\cdot$ Gabriele Kaiser ${ }^{2,3}$ (D) $\cdot$ Mine Işıksal-Bostan $^{4}$ (D)
}

Received: 10 January 2021 / Accepted: 15 August 2021 / Published online: 21 September 2021

(c) The Author(s) 2021, corrected publication 2022

\begin{abstract}
Although the effects of professional development programs on teachers' noticing skills have attracted considerable interest among mathematics education researchers, little is known about the developmental process of prospective teachers' noticing skills within initial teacher education. This paper examines the extent to which prospective teachers' noticing skills are developed through the mathematics education courses taken within the mathematics teachers' education program using exemplarily the topic division of fractions. The study is grounded on the framework of Professional Noticing of Children's Mathematical Thinking which specifies three facets of noticing, that are attending, interpreting, and deciding how to respond. Twenty-two prospective mathematics teachers (PSTs), who were enrolled in the Middle School Mathematics Teacher Education Program at a Turkish university, participated in this study. The results revealed that most PSTs gained expertise in all three kinds of noticing skills during their teacher education. The highest progression could be identified in the interpretation skills and the lowest in attending skills. These results are important for initial teacher education programs, highlighting that general, non-specialized mathematics education courses within initial teacher education have the potential to provide an efficient professional development program to develop PST's noticing skills. The study points out that further research is needed in order to provide additional details about how teacher education programs could be redesigned and implemented to ensure opportunities for PSTs to develop noticing skills within all three facets leading to robust or at least substantial evidence of all three noticing skills.
\end{abstract}

Keywords Teachers' noticing - Professional noticing of children's mathematical thinking $\cdot$ Initial teacher education $\cdot$ Division of fractions

Gabriele Kaiser

gabriele.kaiser@uni-hamburg.de

Extended author information available on the last page of the article 


\section{Introduction}

Recent reforms in mathematics education have highlighted that effective mathematics teaching is challenging, requiring knowing and understanding mathematics, in addition to the ability to manage students' thinking, creating supportive and demanding classroom environments, and identifying noteworthy classroom events, which may support students' learning (Mason, 2002; National Council of Teachers of Mathematics [NCTM], 2000). No recipe exists to make effective teaching easier; however, results of empirical studies found out that keeping students' thinking at the heart of instruction by attending to students' strategies, interpreting their understanding, and making in-the-moment decisions accordingly are a cornerstone of effective teaching (Stockero et al., 2017a, 2017b). Consequently, teachers must have the skills required to notice students' thinking professionally (Jacobs et al., 2010).

Acknowledging the important role of noticing in effective teaching, many studies have been carried out in the past investigating teachers' noticing skills from different perspectives (Jacobs et al., 2010; Star \& Strickland, 2008; Van Es, 2011). However, although noticing is characterized by its domain specificity (Nickerson et al., 2017), only a few studies have explored how teachers' noticing of students' mathematical thinking is shaped by specific mathematical domains (e.g. Ivars et al., 2020; Simsek, 2020). Departing from this research gap on teachers' noticing of students' mathematical thinking in specific mathematical domains, the present study aims to contribute to this research field under two perspectives. First, division of fractions has been focused on as mathematical topic due to its challenging nature based on its conceptual complexity, and its high relevance in mathematics teaching (Tirosh, 2000). Second, as prospective teachers play a prominent role in future mathematics teaching, it is important to explore the extent to which initial teacher education programs promote prospective teachers in professionally noticing students' thinking regarding various mathematical concepts.

\section{Literature Review}

\section{Teachers' Noticing}

Teachers' noticing is focused on teacher's interaction within the classroom as an activation of teachers' knowledge within practice. Therefore, it is regarded as "a process rather than a static category of knowledge" (Sherin et al., 2011, p. 5) and understood in a variety of ways. Based on Goodwin's approach of professional vision (1994), the construct of teachers' noticing was broadened by a socio-cultural perspective including different aspects of teachers' thinking and practices into the understanding of noticing (Jacobs et al., 2010; Kaiser, Busse, Hoth, König \& Blömeke, 2015; Mason, 2002; Sherin et al., 2011). Sherin et al. 
(2011) described two aspects of teachers' noticing that are distinguished in all noticing studies, namely, identifying the important events that occur in the mathematics classrooms and interpreting these events within the instructional setting. In addition to Sherin et al.'s description of teachers' noticing, a third facetdecision-making — has also been adopted by several studies. For example, Kaiser et al. (2015) distinguished three situation-specific skills: “(a) Perceiving particular events in an instructional setting, (b) Interpreting the perceived activities in the classroom, (c) Decision making, either as anticipating a response to students' activities or as proposing alternative instructional strategies" (p. 374). Kaiser et al. (2015) emphasized that this approach includes an overall understanding of quality of mathematics teaching rather than limiting the construct of noticing to specific issues as students' understanding. These situation-specific skills are part of the model of competence as a continuum proposed by Blömeke et al. (2015). Based on this approach, teachers' noticing is assumed to mediate teacher disposition (e.g. knowledge) and teacher performance (Blömeke et al., 2015). Besides, Llinares (2013) discussed the construct of noticing as the relationship between teachers' knowledge of mathematics and professional practice involving several professional tasks, including choosing and forming mathematical tasks, identifying and making sense of students' mathematical thinking, and starting and orchestrating mathematical discussions and interactions in the classroom. More specifically, the skill to "notice professionally" requires "knowing what, how and when to use specific knowledge to solve the mathematics teaching tasks" (Llinares, 2013, p. 79). Based on this understanding, teachers' noticing skills allow teachers to use their knowledge to identify mathematically significant details in a problem and in students' solutions, to interpret students' learning, and to determine the most effective teaching moves. Like Llinares (2013), Jacobs et al. (2010) discussed teachers' noticing from a more specialized perspective by focusing on a particular aspect of teaching-in-the-moment decisions-and particularly on children's mathematical thinking. From this perspective, they defined teachers' noticing as Professional Noticing of Children's Mathematical Thinking.

Within their framework, Jacobs et al. (2010) focused on the construct of noticing by emphasizing students' mathematical thinking as fundamental constituent of noticing. In other words, rather than focusing on how teachers interpret complex classroom environment where many situations are occurring simultaneously (Sherin et al., 2011), Jacobs et al. (2010) narrowed down their focus on how and to what extent teachers notice students' mathematical thinking as individual cognitive activity. Furthermore, they included in the definition of noticing a facet going beyond activities of identifying noteworthy events, interpreting, and reasoning about these events focusing on decision processes. In detail, they described noticing as consisting of the three following facets: attending to children's strategies (i.e. identification of mathematically significant details in students' strategies), interpreting children's understanding (i.e. make sense of students' understanding underpinning their strategies), and deciding how to respond based on children's understanding (i.e. making instructional decisions to respond to students based on their understanding). Jacobs et al. (2010) emphasized that all three skills are intertwined so that the development of each skill depends on each other. 


\section{Domain Specificity of Noticing: Division of Fractions}

Results of empirical studies have confirmed that teachers' professional noticing expertise is domain-specific; consequently, teachers' noticing skills should be investigated in different mathematical domains to identify under a subject-specific perspective, where improvements are required (Ivars, Fernández, \& Llinares, 2020; Jacobs \& Empson, 2016; Nickerson et al., 2017). Based on these results, this study focused on the domain specificity of noticing and selected the context of division of fractions based on the following reasons; division of fractions is a complex topic for students to learn and for teachers to teach (Tirosh, 2000). Furthermore, division of fractions is considered a particularly challenging topic, where students experience many misconceptions and difficulties in conceptually understanding the subject, which demands specific supportive efforts by the teachers (Petit et al., 2010; Tirosh, 2000). To support students, the teachers firstly need to have a deep conceptual understanding from division in connections with fractions by their own (Armstrong \& Bezuk, 1995). However, teachers and students tend to solve tasks by rote, relying on the algorithm rather than on the meaning of division (Unlu \& Ertekin, 2012; Zembat, 2015). Based on the dominance of the rote memorization approach, Ashlock (1990) observed that students and teachers invert both the dividend and the divisor or invert the dividend rather than the divisor. Moreover, Jansen and Hohensee (2016) reported that teachers and students are not able to make sense of representations while dividing fractions. Perlwitz (2005) similarly emphasized that a common difficulty in working with fractions is connected to fraction division problems involving visual representations with related symbolic procedures. Although the students struggle to conceptually understand division of fractions, studies increasingly show that students can invent strategies based on their conceptual interpretations of fractions and its division, and even invent division strategies that include visual representations, using area, linear, or set models (Lamberg \& Wiest, 2015). Although the conceptual understanding of fractions and their multiple representations as well as their operations are empirically often investigated topics focusing on students' understanding, the perspective of teachers' knowledge and teachers' noticing has not been studied widely from the perspective of professional noticing of children's mathematical thinking (exceptions are the studies by Ivars et al., 2020; Simsek, 2020). Thus, it is overdue to analyze teachers' professional noticing in the context of division of fractions to obtain a broader picture of teachers' noticing and contribute to the current state of research.

A wealth of empirical studies point out that teachers' professional noticing can be promoted through specific programs in initial teacher education or professional development (Star \& Strickland, 2008). Recently, many video-based programs, which aim to foster teachers' professional noticing, were developed and show considerable progress of prospective and practicing teachers' noticing, particularly concerning the attending and interpreting/reasoning facets of noticing (for a literature survey see Santagata et al., 2021). It is not an unexpected result that specific intervention activities, which offer - at least prospective - teachers the chance to use their academically acquired knowledge in learning environments, promote professional noticing, especially, when they are supported by video-based activities. Currently, it is an under-researched question, how far 
the professional knowledge-acquired in the common courses in initial teacher education-fosters prospective teachers' noticing skills. Especially when school practical activities are provided, which are of growing importance worldwide, the extent to which prospective teachers' noticing skills are fostered is not yet researched at a broad level (Lawson et al., 2015).

The present study therefore examined the following research question: To what extent are prospective mathematics teachers' (PSTs) noticing skills on the division of fraction promoted through a particular Turkish teacher education program at a (highachieving) Turkish university?

\section{Methodological Approach}

\section{Study Design, Study Participants, and Data Evaluation}

The study was carried out using a qualitative case study design based on three rationales. Firstly, the behavior of the PSTs has not been explicitly influenced during the study and is investigated within its real-life context (Yin, 2003). Secondly, the development of PSTs' noticing skills has to consider the context. Lastly, the study aimed to provide in-depth analysis and rich description of development patterns of the level of PSTs' noticing skills in the context of division of fractions. The focus of the study is one group of PSTs in their 3rd year in a Middle School Mathematics Teacher Education Program at a Turkish university; thus, the study is a single case study. Moreover, since the aim is to investigate PSTs' noticing skills in the context of only one mathematics subject, that is division of fractions, it includes only one unit of analysis. Thus, the study used a single-case holistic design (Yin, 2003).

The study took place over two years implementing a pre-and-post-design. The division of fractions task (DFT) was administered to participants as a pre-test in the 1st year of the study and as a post-test after nearly one year. In the interim, the participants had attended the usual mathematics education courses that included no special interventions to develop PSTs' noticing skills. Overall, the participants were third-year students in their teacher education program during the first year of the data collection procedure and in their final semester during the second year. Twenty-two prospective mathematics teachers were selected from one of the top-ranked universities in Turkey. Students enrolled at this university are required to have scored highly in the nationwide entrance exam; thus, PSTs who participated may be considered as high-achieving students. All participants took the same courses at the same semester during their education at the university. Among them, nineteen (86\%) were female and three (14\%) were male. Pseudonyms (i.e. PST1, PST2 ... PST22) were used for all participants to ensure confidentiality.

\section{Study Context}

This teacher education program where the study was conducted is a four-year program that qualifies graduates working as mathematics teachers in middle schools to 
teach students from grades 5 to 8 . The compulsory courses, included in the program, are common mathematics education courses within initial teacher education focusing on teaching methods for mathematics, school experience and teaching activities in middle school education, and the nature of mathematical knowledge for teaching. Within the teaching methods courses comprising four lessons per week that the PSTs take at their 3rd year of education, students are familiarized with basic school mathematical concepts and the connections between mathematical concepts, real life, and other disciplines, while also acquainting them with students' misconceptions and how to overcoming these using visual representations and manipulatives. Particularly, all PSTs study fractions, such as the conceptual understanding of fractions and operations involving fractions (including division) in these courses. The PSTs take a school experience course in the fall semester of the fourth year including a teaching practicum in the spring semester of the same year. During the school experience course, PSTs observe four lessons taught by mentor teachers in a middle school and share their observations and experiences with their classmates and university instructor in one lesson. They also benefit from fellow PSTs' observations and develop ideas around teaching and learning issues to be used in real mathematics education. The school practicum includes a six-lesson field experience and twolesson-teaching practice. During the two-lesson teaching practice, PSTs explain how they plan to teach the content during their internships, obtain feedback from their university instructors, and report on their field experiences. During the six-lesson field experience, they observe a real classroom, plan and prepare to teach mathematics, and acquire teaching experience under the mentor's guidance. PSTs also study knowledge types and the relationships between them during a course on the nature of mathematical knowledge for teaching, consisting of three lessons per week in the fall semester of their fourth year, in which they become acquainted with common students' mathematical misconceptions and how to deal with them.

The content of the mathematics education courses was not structured towards the promotion of noticing skills. However, students' invented strategies of overcoming students' misconceptions/difficulties and knowledge about the most appropriate teaching methods. The aim of the mathematics education courses was to ensure PSTs with knowledge about how to teach the topic effectively by focusing on students' understanding and the implementation of adequate teaching methods within their school experience.

\section{Data Collection Procedure}

Students' written work was selected as collection method of data rather than using video-based collection methods for the following reasons: According to expertise research (Berliner, Stein, Sabers, Clarridge, Cushing, \& Pinnegar, 1988), inexperienced teachers take the students' behaviors, classroom managements, and classroom settings into consideration rather than students' understanding. As PSTs are inexperienced teachers, they may focus on these issues in the classroom, rather than student thinking. Moreover, the teacher may miss in the video how the student has solved the problem while watching the video and s/he may need to watch it again. 
The focus on the written solutions will put aside any distractions and consideration of unimportant aspects, which may be relevant for classroom management, but not for teachers' noticing.

The importance of the development of fraction division, which is first developed through measurement meaning and common denominator algorithm rather than invert and multiply algorithm, is emphasized in the discourse (Zembat, 2015). From this perspective, the meaning of measurement is the baseline of the division of fraction. In order to understand how PSTs conceptualize the basis of the division, the test Division of Fraction Task (DFT) was developed by the researchers, which consists of one problem involving the measurement meaning of division. The task involved one correct (solution by Katrin) and two incorrect (by Lisa and Marc) solution strategies (Fig. 1).

While implementing the test, it was given strong importance to including representations in each solution as this is important for students' and PSTs conceptual understanding (Charalambous \& Pitta-Pantazi, 2007). Lisa and Marc's approaches include central misconceptions and misunderstandings regarding the division of fractions and important concepts related to fractions and the division algorithm, such as part-whole, equal parts, the meanings of numerator and denominator, and division by a smaller fraction. By presenting Lisa and Marc's strategy to the PSTs, it was expected to find the extent to which their attending, interpreting, and deciding how to respond skills had changed after their practical experiences. On the other hand, Katrin's approach demonstrates the correct use

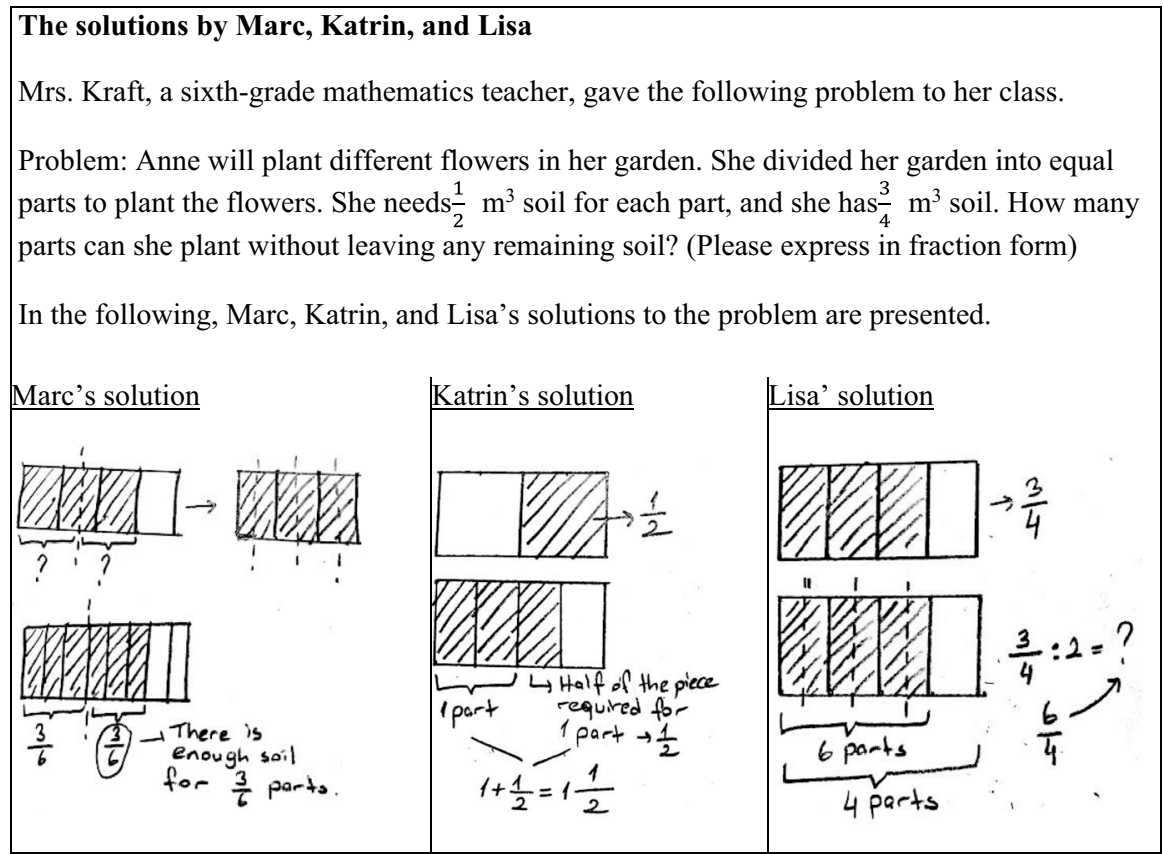

Fig. 1 Division of fractions task (DFT) 
of the area model and correct understanding of the problem, the fraction concept, and fraction division. With this strategy, the PSTs have to conceptualize how Katrin modeled the problem and how she demonstrated the division operation via the area model correctly.

To evaluate PSTs' noticing skills, three questions connected to each task were posed to the participants. Each question addressed a different component of teachers' noticing skills referring to the used framework of Professional Noticing of Children's Mathematical Thinking by Jacobs et al. (2010). The questions were as follows:

a) Explain in detail how Marc, Katrin, and Lisa solved this problem (strategy, etc.). Do you think the solutions of Marc, Katrin, and Lisa are correct? Explain why.

b) Explain in detail what you have learned about Marc, Katrin, and Lisa's understanding of the operation (mathematical conception) based on their solutions?

c) Assume that you are the teacher of Marc, Katrin, and Lisa. What problem or problems would you pose to each student next? Describe in detail each solution.

The first and second questions aimed to examine the extent to which PSTs could articulate the mathematically important details of students' solutions and construct a comprehensive picture of a student's understanding. The third question probed PSTs' in-the-moment decisions regarding students' understanding.

\section{Data Analysis}

The framework by Jacobs et al. (2010) was chosen as evaluative framework for the data analysis in this study as it specifies three facets of noticing differentiated by three attainment levels for noticing, called level of evidence. Despite the general adequacy of the framework, the distinction of only three levels of evidence of each skill remained limited, and more detailed categorization was required for each skill to code the participants' responses. For example, some answers by the PSTs were too strong to be coded as limited evidence but not extensive enough to be coded as robust evidence. Thus, a level named as substantial evidence was added to code the responses that were in their evidence between the limited and robust levels. Based on this slightly extended framework, all data were coded according to four attainment levels, namely lack, limited, substantial, and robust evidence of noticing skills, which are described by precise subject-based indicators. The concrete description of the levels of each skill and the characteristics of each level were developed using an open coding method. In detail, the three facets of teachers' noticing were evaluated along different levels of skills reaching from lack to robust noticing skills. In Table 1, indicators for the evaluation are described in detail.

Two mathematics educators analyzed the data for pre- and post-test jointly and discussed inconsistencies until full consensus was reached. 


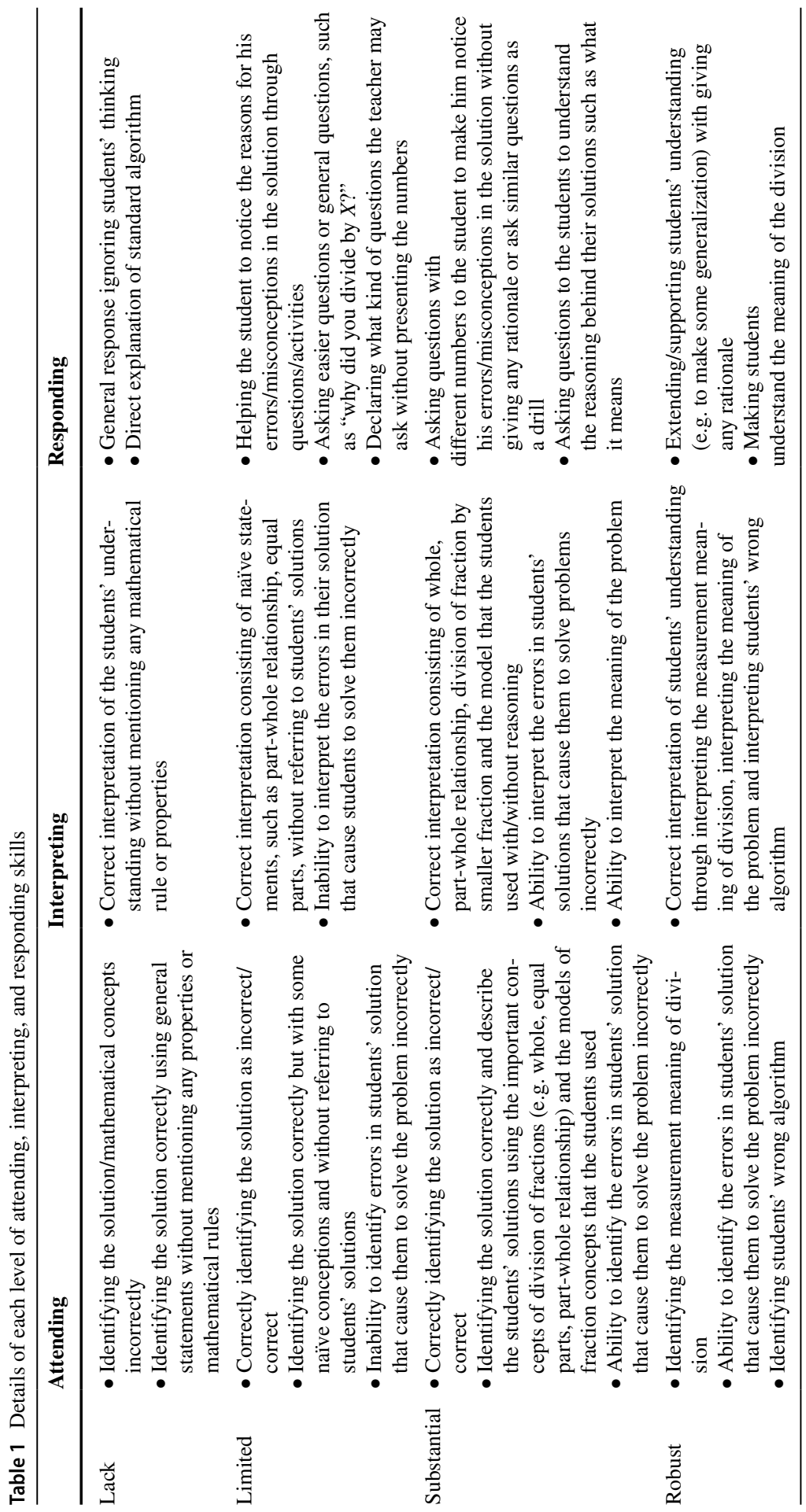




\section{Results}

The study's findings are structured along the three noticing facets to describe the development pattern of the level of PSTs' noticing skills from the lowest to the highest level of evidence from the Professional Noticing of Children's Mathematical Thinking framework. Moreover, exemplary descriptions for changes of the evidence for the different levels attained by the PSTs are provided.

\section{Attending to Children's Strategies}

The frequencies related to PSTs' skills to attend to children's strategies in the study's 1st and 2nd year; also, the changes in each level are presented in Table 2.

As Table 2 illustrates, 8 PSTs demonstrated lack of evidence in the 1st year of the study; however, seven PSTs who showed lack of evidence of skills to attend to children's strategies began to exhibit stronger evidence ( 2 of them progressed to limited, 5 of them progressed to substantial). Overall, the greatest progress was seen in those who were originally very weak concerning this noticing facet. However, this progress is limited to substantial evidence, which means that the PSTs who provided lack of evidence of attending to children's strategies in the 1st year could provide substantial evidence in the 2 nd year of the study. Additionally, three PSTs progressed their attending skill from limited to substantial. It is surprising that one PST decreased the attending skill from substantial to lack in the 2nd year. Moreover, only one additional PST (PST5) increased the attending skills from substantial to robust by identifying the measurement meaning of fraction division.

Developmental Pattern from Lower to Robust Evidence of Attending to Children's Strategies PST5 exhibited substantial evidence in the 1st year and increased the performance to a robust level of attending to children's strategies in the 2nd year, which is described exemplarily in the following. PST5 attended to Marc's solution in the 1st year and 2nd year as shown in Table 3 (translations from Turkish into English provided by the first and third authors).

Table 2 Frequencies of each level of attending skills in the first and second year of the study and the changes in each level $(n=22)$

\begin{tabular}{lllllll}
\hline Changes in each level & & & & \\
\hline & 1st year & Lack & Limited & Substantial & Robust & 2nd year \\
\hline Lack & 8 & 1 & -2 & $-5 /+1$ & 0 & 2 \\
Limited & 4 & +2 & 1 & -3 & 0 & 3 \\
Substantial & 8 & $+5 /-1$ & +3 & 6 & -1 & 14 \\
Robust & 2 & 0 & 0 & +1 & 2 & 3
\end{tabular}

The (-) sign corresponds to the number of PST that changed the attending skills from the level specified in the row to the level specified in the column; the $(+)$ sign corresponds to the number of PST that changed the attending skills from the level specified in the column to the specified level in the row. Unsigned numbers correspond to the number of PSTs remaining at the same level. 
Table 3 Exemplary development of attending skill from substantial to robust level

\begin{tabular}{ll}
\hline 1st year & The question actually asks us how many $1 / 2$ pieces correspond to $3 / 4$. Marc at first showed $3 / 4$ \\
Substantial & correctly using area model and divided $3 / 4$ by 2 . Knowing that each part should be equal, he \\
then divided each $1 / 4$ by 2 . However, he took thewhole as $3 / 4$ and ignored $1 / 4$, which was not \\
shaded
\end{tabular}

In the study's 1st year, PST5 could correctly identify the solution as incorrect/ correct and describe the students' solutions using important concepts in division of fractions (e.g. equal parts, part-whole relationship) and the models of fraction concepts that the students used. Moreover, she could identify the whole correctly and the errors in students' solutions that caused them to approach the problem incorrectly. However, she presented no information related to students' understanding of the meaning of division operation. In the study's 2nd year, PST5 captured the mathematical details of Marc's solution by identifying the partition meaning of division in addition to her attention in the first year. These changes indicate that PST5 had improved her attending skills from a substantial to a robust level.

\section{Developmental Pattern from Lower Evidence to Substantial Evidence of Attending to Children's Strategies Table 2 displays that the number of PSTs who showed sub-} stantial evidence of attending to students' solutions in the study's 1st and 2nd years were 8 and 14, respectively. Some PSTs' levels of attending increased in the study's 2nd year. Although five PSTs increased their level of attending from lack to substantial and three increased their level from limited to substantial, six PSTs' levels of attending remained at the substantial level. As an illustrative example, PST17's attending to Lisa's solution is given in Table 4.

While PST17 described the students' solutions at the study's 1st year, he did not mention equal parts, what the whole was, or what the students thought about the whole, and he could not explain the meaning of the division operation. In the 2nd year of the study, however, PST17 described Lisa's solution based on the mathematically important details of the division of fractions, attending to equal parts, the whole, and errors in students' solutions that caused them to solve the problem incorrectly. Similarly, the PSTs who showed substantial evidence of attending skills could 
Table 4 Exemplary development of attending skill from limited to substantial level

\begin{tabular}{ll}
\hline $\begin{array}{l}\text { 1st year } \\
\text { Limited }\end{array}$ & $\begin{array}{l}\text { Lisa thought that the operation she required was } 3 / 4 \div 2 \text {.First, she divided thewhole into four } \\
\text { parts and shaded three parts to present Anne's garden. Then, she divided each shaded } 1 / 4 \\
\text { into two and got six parts. Then, she proportioned } 6 \text { partsto } 4 \text { parts }\end{array}$ \\
\hline $\begin{array}{l}\text { 2nd year } \\
\text { Substantial }\end{array}$ & $\begin{array}{l}\text { In this question, while Marc and Lisa's solutions are wrong, Katrin's solution is correct. } \\
\text { The question actually asks how many } 1 / 2 \text { pieces correspond to } 3 / 4 \text {. Like Marc, Lisa } \\
\text { divided 3/4 into two in her modeling, but unlike Marc, she took the whole correctly. She } \\
\text { forgot that all parts should be equal to each other. She proportioned six parts to four parts } \\
\text { but did not realize that these ratios do not express the same fraction units. In other words, } \\
\text { she did not notice that the size of } 6 \text { parts and the size of } 4 \text { parts did not equal to each } \\
\text { other. She misunderstood the meaning of the mathematical expression } 3 / 4 \div 2 \text {, but found } \\
\text { the answer correct accidentally }\end{array}$
\end{tabular}

not present any information related to students' understanding of the meaning of the division operation.

\section{Interpreting Children's Understanding}

The frequencies related to PSTs' interpreting skills in the study's 1st and 2nd years and also the changes in each level are illustrated in Table 5.

As seen in Table 5, three PSTs among nine progressed their interpretation skills from lack to limited and five of them progressed from lack to substantial. As seen for attending skill, the greatest progress took place for PSTs moving from the level lack of evidence to higher levels. Moreover, 5 PSTs showed substantial evidence in the 2nd year even though they showed limited evidence of interpretation in the 1st year. Fewer PSTs improved their interpreting skills to the robust level, which required interpreting the measurement meaning of division of fractions.

Developmental Pattern from Lower Evidence to Robust Evidence of interpreting Children's Understandings The data point out that, although none of the PSTs showed

Table 5 Frequencies of each level of interpreting skills in the first and second years of the study and the changes in each level $(n=22)$

\begin{tabular}{lllllll}
\hline & & \multicolumn{2}{l}{ Changes in each level } & \\
\cline { 3 - 6 } & 1st year & Lack & Limited & Substantial & Robust & 2nd year \\
\hline Lack & 9 & 1 & -3 & -5 & 0 & 1 \\
Limited & 8 & +3 & 2 & $-5 /+1$ & -1 & 6 \\
Substantial & 5 & +5 & $+5 /-1$ & 3 & -1 & 13 \\
Robust & 0 & 0 & +1 & +1 & 0 & 2 \\
\hline
\end{tabular}

The - sign corresponds to the number of PST that changed the interpreting skills from the level specified in the row to the level specified in the column; the + sign corresponds to the number of PST that changed the interpreting skills from the level specified in the column to the specified level in the row. Unsigned numbers correspond to the number of PSTs remaining at the same level. 
robust evidence of interpreting skills in the study's 1st year, two demonstrated robust evidence in the 2nd year. More specifically, one PST who showed limited evidence and one PST who showed substantial evidence in the 1st year developed their interpreting skills to the robust level in the 2nd year. PST14's interpretation is given as an example (Table 6).

In the study's 1st year, PST14 interpreted the problem correctly with respect to the whole and the part-whole relationship and interpreted the problem and the errors in their solutions that caused the students to solve them incorrectly. However, she presented no information related to students' understandings of the meaning of the division operation. In the study's 2nd year, PST14 captured the mathematical details of the students' solutions by identifying the measurement meaning of division in addition to her interpretation in the 1st year.

As it is clear from PST14's explanation, she explained the students' understanding based on the meaning of the division operation by providing reasoning; thus, she improved her interpreting skills from the substantial to the robust level.

Developmental Pattern from Lower Evidence to Substantial Evidence of Interpreting Children's Understandings Although five PSTs demonstrated substantial evidence in the study's 1st year, 13 PSTs showed substantial evidence of interpreting in the 2nd year. Of these 13 PSTs, five who showed lack and limited evidence in the 1st year developed their interpretation skills to substantial; however, three PSTs' interpreting skills remained the same. As an illustrative example, PST8's interpretation is given in Table 7.

Table 6 Exemplary development of attending skill from substantial to robust level

\begin{tabular}{ll}
\hline 1st year & First of all, Marc did not understand what was asked in the question. So, theconcepts of \\
Substantial & finding the half of a whole and how many $1 / 2$ there are in the whole are not understood. In \\
addition, he focused on $3 / 4$ of the whole rather than focusing $4 / 4$. I mean that he changed \\
the whole. So, he does not understand the fraction concept \\
Lisa used a similar solution to Marc. She divided the $3 / 4$ pieces, which she showed with \\
fraction parts into 2 identical parts and then since there are 6 small parts and 4 small parts, \\
she said $6 / 4$. She was unaware of not these pieces are equivalent and what they repre- \\
sents. She also thought that it was asking how many 2 s there are in $3 / 4$ and she did this \\
algorithm wrong \\
The division has 2 meanings: partition and measurement. In partition meaning, when I \\
divide $3 / 4$ by 2 , it means that when I share a $3 / 4$ piece between 2 people, how much does \\
Robust \\
each person get? If the operation is $3 / 4 \div 1 / 2$, then how can I define this operation by the \\
partition meaning? I can't share $3 / 4$ to half a person. This would be nonsense. Instead, I \\
can say how many $1 / 2$ are in $3 / 4$. This makes more sense and the problem involves this \\
meaning of the division measurement. Marc and Lisa did not consider the measurement \\
meaning of division. They took the partition meaning of division into consideration so \\
they tried to divide by 2 . Also, Marc did not know that the whole did not change and Lisa \\
did not know that all the parts should be equal. I mean that they did not comprehend the \\
part-whole relationship and equal parts concept
\end{tabular}


Table 7 Exemplary development of interpreting skill from lack to substantial

\begin{tabular}{ll}
\hline $\begin{array}{l}\text { 1st year } \\
\text { Lack }\end{array}$ & $\begin{array}{l}\text { I can see that Marc and Lisa had deficiencies in operations in fractions. Both of them could } \\
\text { draw the figure of 3/4, but they did not understand the operation needed to solve the prob- } \\
\text { lem. They also did not know how to write the solution as a mathematical expression }\end{array}$ \\
\hline $\begin{array}{l}\text { 2nd year } \\
\text { Substantial }\end{array}$ & $\begin{array}{l}\text { Marc and Lisa struggle to understand the part-whole relationship and the meaning of } \\
\text { division. We cannot proportion the parts that are not equal to each other. However, Lisa } \\
\text { proportioned } 6 \text { parts to } 4 \text { parts, although the size of the } 1 \text { part of } 4 \text { parts is not equal to } \\
\text { the size of the } 1 \text { part of } 6 \text { parts. On the other hand, Marc took } 3 / 4 \text { as a whole, but he can- } \\
\text { not change the whole that was given at the beginning }\end{array}$
\end{tabular}

This example shows that PST8's interpretation included no mathematical concepts; rather, she used general statements in the study's 1st year. However, in the 2nd year, she interpreted students' understanding depending on highly important mathematical details, and her level of interpretation skill was promoted in the 2 nd year.

\section{Developmental Pattern from Lower Evidence to Limited Evidence of Interpreting} Children's Understandings As shown in Table 5, while eight PSTs showed limited evidence of interpreting in the study's 1st year, this decreased to six in the 2nd year. Of these six PSTs, three showed lack of evidence in the 1st year. This means that three PSTs developed their level from lack to limited. To clarify the development from the lack to limited level of evidence, PST9's interpretation is displayed in Table 8 .

In the study's 1st year, PST9 interpreted students' understanding without referring to mathematical concepts; however, in the 2nd year, she used general statements, such as referring to the "whole" independently of the students' solutions.

To sum up, 20 PSTs developed their interpreting skills by providing more detailed information about students' understanding, 15 PSTs provided evidence for their interpretation skills at the two highest levels.

\section{Deciding How to Respond Based on Children's Understanding}

The frequencies related to PSTs' deciding skills in the study's 1st and 2nd years and also the changes in each level are presented in Table 9.

Table 9 displays that all PSTs who had shown a lack of evidence developed their skills in deciding how to respond based on children's understanding. Four PSTs developed their responding skills from the level "lack of evidence" to the level "substantial evidence" in the study's 2nd year while only two began to respond to students with

Table 8 Exemplary development of interpreting skill from lack to limited level

\begin{tabular}{ll}
$\begin{array}{l}\text { 1st year } \\
\text { Lack }\end{array}$ & $\begin{array}{l}\text { Marc was successful at modeling, but he did not understand the problem. He tried to do } \\
\text { something, but all his attempts were incorrect }\end{array}$ \\
\hline $\begin{array}{l}\text { 2nd year } \\
\text { Limited }\end{array}$ & $\begin{array}{c}\text { Marc had difficulty in understanding what the whole is. He took the shaded area as the whole } \\
\text { but did not consider the non-shaded area }\end{array}$ \\
\hline
\end{tabular}


Table 9 Frequencies of each level of deciding how to respond skill in the first and second years of the study and the changes of each level $(n=22)$

\begin{tabular}{llllllll}
\hline & & & \multicolumn{3}{l}{ Changes in each level } & \\
\cline { 5 - 7 } & 1st year & & Lack & Limited & Substantial & Robust & 2nd year \\
\hline Lack & 6 & 0 & -1 & -4 & -1 & 0 \\
Limited & 9 & +1 & 3 & $-5 /+2$ & -1 & 6 \\
Substantial & 6 & +4 & $+5 /-2$ & 4 & 0 & 13 \\
Robust & 1 & +1 & +1 & 0 & 1 & 3 \\
\hline
\end{tabular}

The - sign corresponds to the number of PST that changed the responding skills from the level specified in the row to the level specified in the column; the + sign corresponds to the number of PST that changed the responding skills from the level specified in the column to the specified level in the row. Unsigned numbers correspond to the number of PSTs remaining at the same level.

robust evidence. However, two PSTs decreased their responding skills from a substantial level to limited level. As in the case of attending and interpreting skills, the greatest progress occurred at the level of lack of evidence.

\section{Developmental Pattern from Lower Evidence to Robust Evidence of Responding} to Children's Understandings. Only one PST showed robust evidence of responding skills in the study's 1st year but two gained greater expertise in responding and increased their level of evidence from lack and limited to robust in the 2 nd year. PST15's response to students' solutions as a next teaching move is provided as an example (Table 10).

PST15 gave general responses without stating what problem he planned to pose in the study's 1st year. However, the aim of PST15's next teaching move in the study's 2nd year was to help students distinguish the partition and measurement meanings

Table 10 Exemplary development of responding skill from lack to robust level

1st year Since Marc and Lisa didn't understand the problem, I would make them read it again. If they Lack found the same result, I wouldn't have asked the same problem until they could solve the problem using the correct strategy and could understand the problem. Instead, I would ask a simpler question

2nd year Since Marc and Lisa could not solve the problem, I realized that this problem is not suitable Robust for their level of understanding. Thus, first, I would give story problems and ask which operation is required. For example, if I have 12 sugars and each person takes 4, how many people will take sugar? Also, I have 12 sugar pieces and I want to distribute them among 4 children. How many sugar pieces does each child get? What operation will you use to solve each problem? Why is that? Is there any difference between these problems? First, I would make them perform the operation with whole numbers and help them realize the meanings of the division operation. Then I would increase the difficulty and ask the following: I have 12 loaves of bread and I would like to distribute these breads so that each person will get half a loaf. In this case, how many people will get bread? With this question, I would aim to help them make sense of the division operation in fractions 
of the division operation by asking questions that include whole numbers. She also aimed to help students generalize their operations by transferring their understanding to the standard algorithm.

Developmental Pattern from Lower Evidence to Substantial Evidence of Responding to Children's Understandings Although six PSTs demonstrated substantial evidence in the study's 1st year, 13 PSTs showed substantial evidence of responding in the 2nd year. Among these 13, five PSTs who displayed limited evidence and 4 PSTs who showed a lack of evidence in the 1st year developed their responding skills to the level of substantial evidence. To illustrate these changes, PST21's development of her responding skill is presented in Table 11.

This example shows that PST21 tried to help students recognize their errors/misconceptions by asking questions related to their solution and aimed to reveal the reasons for their mistakes in the study's first year. However, in the second year, she asked the question using easier numbers to help the students who had solved the problem incorrectly to notice their misconception. Moreover, she asked similar questions as exercise for the students who had solved the problem correctly rather than extending their understanding.

Developmental Pattern from Lower Evidence to Limited Evidence of Responding to Children's Understandings Nine and six PSTs showed limited evidence of responding skills in the 1st and 2nd years of the study, respectively. Some of the PSTs demonstrating limited evidence in the 1st year developed their responding skills to a level of substantial and robust evidence. Only one PST improved her responding skills from lack to limited while others' skill levels remained the same. PST4's response is given below to illustrate the development of responding skill from the level of lack to limited evidence (Table 12).

In the study's 1st year, PST4 provided general responses without focusing on the students' solutions. Moreover, the questions that she proposed were not clear.

Table 11 Exemplary development of responding skill from limited to substantial level

\begin{tabular}{ll}
\hline 1st year & I would ask some questions to help Marc and Lisa notice their mistakes \\
Limited & For Marc: what is the whole? What do you understand from the problem? Why did you \\
divide by 2 ? What does $3 / 6$ mean? \\
For Lisa, what does $6 / 4$ mean? What does the fraction mean? Did you divide the whole \\
into equal parts? When you divide the fraction in two, is the result bigger or smaller than \\
the fraction? What does the problem ask? \\
For Katrin, can you solve the problem using different numbers? \\
I would ask Katrin a problem that she could not solve by modeling
\end{tabular}

2nd year

For Marc and Lisa, if Anne has $1 \mathrm{~m}^{3}$, what would be the answer? Why? How did you

Substantial find this? If Anne has $3 / 4 \mathrm{~m}^{3}$, what changes? Why did you take half of the 6 pieces? [to Marc]. Why did you divide 6 by 4 ? [to Lisa]

For Katrin, if Anne has $1 / 2 \mathrm{~m}^{3}$, then what would the answer be? Why? How did you arrive at this? If Anne has $1 / 4 \mathrm{~m}^{3}$, then what would the answer be? How did you arrive at this? 
Table 12 Exemplary development of responding skill from lack to limited level

1st year I would ask Marc and Lisa what they understood from the problem. Thus, I can learn whether Lack they had misconceptions or did not understand the problem. I would ask the next question based on their answer

2nd year I would ask Marc and Lisa the meaning of the fractions. I wanted them to show $3 / 4$ in the

Limited whole and asked them how many $1 / 2$ in $3 / 4$. In this way, I would try to help them understand the problem's meaning

However, in the 2nd year, she asked questions to help students realize their errors by asking about the problem's meaning. Thus, she improved her responding skill from the level of lack to limited evidence.

Similar to the development of attending and interpreting skills, 18 PSTs improved their responding skills, and most importantly, 16 PSTs provided evidence for responding skills at the two highest levels.

In conclusion, although some of the PSTs' noticing skills' levels remained at the same level, most PSTs gained expertise in all three noticing skills during the mathematics education courses offered within their initial teacher education program and developed their noticing skills through enrollment in the teacher education program. More specifically, data analysis showed that $64 \%$ of PSTs developed their attending skills after they had taken the mathematics education courses. Furthermore, 90\% and $82 \%$ of them made a positive shift towards higher levels of interpreting and responding skills. In other words, during the study, strong developments concerning fostering PSTs' interpreting skills took place, with the lowest change concerning the attending skills.

\section{Summary of the Results and Discussion}

The study presents findings that described the detailed development of the three interrelated facets of teachers' noticing in the context of division of fractions within an established program of initial mathematics teacher education. In the following, the study's findings will be discussed based on two aspects: comparison of the changes between different facets of the PSTs' noticing skills and the influence of mathematics education courses within initial teacher education on the development of PSTs' noticing skills.

\section{Comparison of the Changes Among the PSTs' Noticing Skills}

Data analysis showed that the extent of change among noticing skills differed, indicating that the mathematics education courses without special interventions affected each skill differently. The reason for these differences may be explained through the number of PSTs who showed substantial and robust evidence in the study's 1st year. It emerged that more PSTs could already attend to students' solution strategies providing substantial and robust evidence before taking any mathematical education 
courses; however, fewer PSTs could interpret students' understanding and respond to them by demonstrating substantial and robust evidence. In other words, before the PSTs took any courses, their attending skills were already more developed than the interpreting and responding skills, which corroborates several studies' findings (Gonzalez \& Skultety, 2018; Jacobs et al., 2010; Sanchez-Matamoros et al., 2015). For instance, Gonzalez and Skultety (2018) stressed that mathematics teachers already showed higher evidence of attending from their study's outset. This highlights the gap between descriptions of the students' solutions based solely on mathematically significant details, and reflecting these descriptions to interpreting students' understanding and responding to the students based on their understanding.

However, after taking the mathematics education courses, almost the same number of PSTs showed higher levels of evidence for all three skills. Thus, it appears that fewer PSTs developed their attending skills while more PSTs developed their interpreting and responding skills. In other words, while mathematics education courses ensured the development of more PSTs' interpreting and responding skills, they contributed to the development of fewer PSTs' attending skills. Interestingly, this comparison revealed that more PSTs need greater support to develop their interpreting and responding skills than to develop attending skills. Differences between the three skills may explain why different levels of support are necessary. As Jacobs et al. (2010) specified, the skill of attending to students' strategies requires the teacher to recognize the mathematical details embedded in students' strategies. The change in the attainments of fewer PSTs showed that most PSTs already possessed knowledge about the details in the students' solutions. Referring to Ball et al. (2008), to describe students' strategies using mathematically significant concepts with appropriate mathematical language, the teacher must have mathematical knowledge. This result indicated that PSTs' previous experiences as learners and their prior knowledge are significant indicators of their attending behavior and extent, as several researchers have noted (Casey et al., 2018; Star \& Strickland, 2008). Furthermore, Casey et al. (2018) reported that mathematical knowledge is regarded as fundamental to the skill of attending to students' strategies. Moreover, Ballock et al. (2018) indicated that well-developed knowledge of students and content plays a vital role in attending to students' strategies with wider perspectives.

On the other hand, interpreting skills are based on reasoning regarding what the students understand mathematically (Sherin \& Van Es, 2009). To reason about students' understanding based on their solutions, teachers must first describe the mathematically important details of students' solutions (Jacobs et al., 2010). It is difficult to interpret students' understanding without attending to the details in their strategies. Although most of the PSTs could attend to students' solution strategies before taking any mathematics education courses, they struggled to interpret students' understanding. This result showed that attending to students' solutions is not itself sufficient to interpret their understanding. To develop expertise in interpreting, teachers must comprehend mathematical ideas (Fernandez et al., 2013) and have content knowledge, which plays a foundational role in interpreting (Casey et al., 2018). Because mathematics education courses allowed the PSTs to improve their attending skills, as revealed by the present study's data, and to acquire knowledge about mathematical concepts, this may 
have influenced the improvement of PSTs' interpreting skills. In addition to learning the concepts' important details, the PSTs could experience assessing students' understanding throughout the mathematics education courses. These experiences may have enabled PSTs to enhance their interpreting skills.

Moreover, the skill of deciding how to respond to students' approaches requires the teachers to make decisions regarding their next instructional moves based on their interpretation of the students' mathematical understanding (Jacobs et al., 2010). Several researchers have asserted that teachers struggle to decide how to respond in a way that will support and extend their students' current understanding (Jacobs et al., 2011). Consistent with this result, most PSTs struggled to further develop students' understanding at the beginning of the study. After attending mathematics education courses, they began to respond to students with the aim of supporting and extending their understanding. One factor that enabled PSTs to improve their responding skills might be the improvement of their attending and interpreting skills. This is not unexpected, since responding skills are embedded in attending and interpreting skills, meaning that expertise in attending to student's strategies and interpreting their understandings are indicators of PSTs' level of responding skills (Jacobs et al., 2011). Moreover, similar to attending and interpreting skills, the PSTs learned the most appropriate teaching strategies/representations/models, acquired knowledge about students' possible misconceptions and ways of dealing with these misconceptions, and how to extend and support students' understanding during their mathematics education courses. From this perspective, this study revealed that the PSTs' responding skills were enhanced when their attending and interpreting skills were enhanced and when they become more knowledgeable about mathematical concepts by means of the mathematics education courses. The improvement of responding skills of PSTs may be an answer to the question posed by Fisher et al. (2019) on how to improve responding skills. Although they reported that attending and interpreting skills could be developed with appropriate intervention, they were in doubt about the improvement of responding skills and claimed it needs further discussion. The results of the current study showed that PSTs may gain greater expertise in responding skills within knowledge-based courses within initial teacher education.

As hypothesized, all three skills were developed through mathematics education courses taken within teacher education programs. The notable issue that should be emphasized is that all skills developed within knowledge-based courses on mathematics and mathematics pedagogy are provided during initial teacher education. Although the strengths of changes in the skills varied, the lowest level skill—attending - progressed less, which is explainable taking the knowledge-orientation of the courses into account. As the relationship between the three skills is considered, the necessity of more support for the development of interpreting and responding skills is unsurprising since both skills are more challenging than attending skills, with which they are connected. 


\section{The Influence of Mathematics Education Courses on the Development of Prospective Teachers' Noticing Skills}

Teachers' noticing skills are a crucial component of effective mathematics teaching, and thus, it is necessary to support PSTs in learning to notice students' mathematical thinking (Star \& Strickland, 2008; Van Es, 2011). Accordingly, a growing body of research aimed to investigate ways to develop PSTs' noticing skills (Jacobs et al., 2010) and implement various professional development programs (Amador $\&$ Carter, 2018). In contrast to the results of these studies, a key finding of the present study is that PSTs may improve their noticing skills through knowledge-based mathematics education courses in the teaching education program complemented by practical school activities without any specific noticing intervention. This highlights the importance of knowledge-based mathematics education courses and practically oriented courses within teacher education program in eliciting and developing PSTs' noticing skills, as several other researchers have observed (Star \& Strickland, 2008; Star et al., 2011). However, the results of earlier studies have emphasized that PSTs' noticing skills may be developed through special tasks implemented during mathematics methods courses. At this point, this study contributes significantly to the field of mathematics education by concluding that knowledge-based courses complemented by practical school activities play a central role in the promotion of PSTs' noticing skills. In other words, the result has significance for teacher education programs as it highlights that content-based and practice-oriented teacher education programs - which allow PSTs to analyze students' strategies, convey detailed knowledge about students' thought patterns, facilitate discussion about their understanding, and explore the issue of instructional decisions as to next moves on the basis of students' understanding - are efficient professional development programs in developing prospective teachers' noticing skills, as Star and Strickland (2008) have noted. Furthermore, the result may provide some theoretical and practical implications related to development of PSTs' noticing skills through the courses taken within initial teacher education programs that included no special interventions for other contexts, which have similar teacher education programs. Thus, mathematics teacher educators have an ongoing responsibility to design their courses in such a way as to enhance PSTs' noticing skills, as Roth McDuffie et al. (2014) stated. In this manner, apart from developing PSTs' participation in professional development programs or special interventions, all PSTs educated in teacher education programs will surely develop and improve their noticing skills.

However, many researchers have also demonstrated that video analysis and lesson study are effective tools for improving PSTs' noticing (Jacobs et al., 2011; Sherin \& van Es, 2009; Star et al., 2011). The reason for this contradiction may be the courses' content and implementation. The content-based courses cover the mathematically significant concepts related to division of fractions, students' misconceptions, their causes, and ways to overcome these misconceptions. These courses were implemented via the discussion of students' solution strategies in which PSTs reflect their understanding. Ways of extending students' conceptual understanding and supporting their procedural knowledge with underlying reasoning are also discussed throughout these courses. In this way, the PSTs internalize the importance of 
students' thinking and the effect of making students' thinking central to the lesson. Since the skills of professional noticing are based on students' understanding, the content and implementation of the content-based courses supported PSTs in improving their noticing skills. Apart from content-based courses, this study's results revealed that practice-oriented courses play a vital role in enhancing PSTs' noticing skills. These courses provide an environment for real classroom observations and interaction with students in an application-based environment, providing a context conducive to the development of PSTs' noticing skills. While the PSTs were taking the content-based courses, they became familiar with the real classroom environment, including different features of the teaching profession under the guidance of mentor teachers, students with different cognitive levels, and teachers with different teaching experiences. Through the implementation of practice-oriented courses, PSTs have begun to attend to students' strategies by considering mathematically significant details of the concept, interpreting students' understanding more comprehensively, and making more effective pedagogical decisions as they acquired greater experience. This remarkable result confirmed that PSTs' noticing skills might be developed through teaching practice and practical experiences with the interactions between PSTs and students and mentor teachers around the students' mathematical thinking (Stockero et al., 2017a, 2017b). In relation to this, Lu et al. (2020) have suggested that mentoring under the guidance of experienced teachers is vital for fostering teachers' professional noticing.

\section{Limitations and Further Research}

Although the study's results provide significant information related to the development of PSTs' noticing skills through the courses taken within initial teacher education programs that included no special interventions, the study has several limitations. This study was limited to PSTs enrolled in one of Turkey's most selective universities, and thus, the findings may not reflect the situation in other Turkish universities. Another limitation of the study is that PSTs' noticing skills were assessed within the context of division of fractions. The complex nature of division of fractions might influence the development of PSTs' noticing skills within the scope of mathematics education courses. The focus on different mathematics domains may have influenced the degree of change in the three noticing skills. Moreover, the data collection process was restricted to the test division of fraction task (DFT) containing students' written work, whereas the interview is a valuable source for understanding someone's thoughts (Yin, 2003). So, further studies enriched with interviews might be conducted to learn more about the development process of PST's noticing skills through the courses taken within initial teacher education programs. Additionally, further research is needed in order to provide additional details about how teacher education programs could be redesigned and implemented to ensure opportunities for PSTs to demonstrate robust and at least substantial evidence of all three noticing skills. Furthermore, this study's findings are based on the teacher education program in a single Turkish university. Thus, the study needs to be replicated in different universities in Turkey and cross-culturally to investigate the effect 
of mathematics education courses on teachers' noticing skills. Overall, the influence of knowledge-based courses and practically oriented courses in initial teacher education programs from other countries needs to be taken into account in order to reveal more robust and generalizable results.

However, the results are encouraging as they point out the impact of initial teacher education on the performance of PSTs, the high relevance of domain-specific courses, and the high relevance of practice in transforming academic knowledge into the situation-specific skills of noticing.

Funding Open Access funding enabled and organized by Projekt DEAL.

\section{Declarations}

Conflict of Interest The authors declare no competing interests.

Open Access This article is licensed under a Creative Commons Attribution 4.0 International License, which permits use, sharing, adaptation, distribution and reproduction in any medium or format, as long as you give appropriate credit to the original author(s) and the source, provide a link to the Creative Commons licence, and indicate if changes were made. The images or other third party material in this article are included in the article's Creative Commons licence, unless indicated otherwise in a credit line to the material. If material is not included in the article's Creative Commons licence and your intended use is not permitted by statutory regulation or exceeds the permitted use, you will need to obtain permission directly from the copyright holder. To view a copy of this licence, visit http://creativecommons.org/licen ses/by/4.0/.

\section{References}

Amador, J. M., \& Carter, I. S. (2018). Audible conversational affordances and constraints of verbalizing professional noticing during prospective teacher lesson study. Journal of Mathematics Teacher Education, 21(1), 5-34.

Armstrong, B. E., \& Bezuk, N. (1995). Multiplication and division of fractions: The search for meaning. In J. T. Sowder \& B. P. Schappelle (Eds.), Providing a foundation for teaching mathematics in the middle grades (pp. 85-119). State University of New York Press.

Ashlock, R. D. (1990). Error patterns in computation. Macmillan.

Ballock, E., McQuitty, V., \& McNary, S. (2018). An exploration of professional knowledge needed for reading and responding to student writing. Journal of Teacher Education, 69(1), 56-68.

Ball, D. L., Thames, M. H., \& Phelps, G. (2008). Content knowledge for teaching: What makes it special? Journal of Teacher Education, 59(5), 389-407.

Berliner, D. C. , Stein, P., Sabers, D., Clarridge, P.B., Cushing, K., \& Pinnegar, S. (1988). Implications of research on pedagogical expertise and experience for mathematics teaching. In D. A. Grouws, T.J. Cooney, \& D. Jones (Eds.), Effective mathematics teaching. Vol. 1 (pp. 66-95). Reston, VA: Lawrence Erlbaum.

Blömeke, S., Gustafsson, J.-E., \& Shavelson, R. J. (2015). Beyond dichotomies: Competence viewed as a continuum. Zeitschrift Für Psychologie, 223(1), 3-13.

Casey, S., Lesseig, K., Monson, D., \& Krupa, E. E. (2018). Examining pre-service secondary mathematics teachers' responses to student work to solve linear equations. Mathematics Teacher Education and Development, 20(1), 132-153.

Charalambous, C., \& Y., \& Pitta-Pantazi, D. (2007). Drawing on a theoretical model to study students' understanding of fractions. Educational Studies in Mathematics, 64, 293-316.

Fernández, C., Llinares, S., \& Valls, J. (2013). Primary school teacher's noticing of students' mathematical thinking in problem solving. The Mathematics Enthusiast, 10(1), 441-468. 
Fisher, M. H., Thomas, J., Jong, C., Schack, E. O., \& Dueber, D. (2019). Comparing preservice teachers' professional noticing skills in elementary mathematics classrooms. School Science and Mathematics, 119(3), 142-149.

Gonzalez, G., \& Skultety, L. (2018). Teacher learning in a combined professional development intervention. Teaching and Teacher Education, 71(1), 341-354.

Goodwin, C. (1994). Professional vision. American Anthropologist, 96(3), 606-633.

Ivars, P., Fernández, C., \& Llinares, S. (2020). A learning trajectory as a scaffold for pre- service teachers' noticing of students' mathematical understanding. International Journal of Science and Mathematics Education, 18(3), 529-548.

Jacobs, V. R., \& Empson, S. B. (2016). Responding to children's mathematical thinking in the moment: An emerging framework of teaching moves. ZDM-Mathematics Education, 48(1-2), 185-197.

Jacobs, V. R., Lamb, L. L. C., \& Philipp, R. A. (2010). Professional noticing of children's mathematical thinking. Journal for Research in Mathematics Education, 41(2), 169-202.

Jacobs, V. R., Lamb, L. C., Philipp, R. A., \& Schappelle, B. P. (2011). Deciding how to respond on the basis of children's understandings. In M. G. Sherin, V. R. Jacobs, \& R. A. Philipp (Eds.), Mathematics teacher noticing: Seeing through teachers' eyes (pp. 97-116). Routledge.

Jansen, A., \& Hohensee, C. (2016). Examining and elaborating upon the nature of elementary prospective teachers' conceptions of partitive division with fractions. Journal of Mathematics Teacher Education, 19(6), 503-522.

Kaiser, G., Busse, A., Hoth, J., König, J. \& Blömeke, S. (2015). About the complexities of video-based assessments: Theoretical and methodological approaches to overcoming shortcomings of research on teachers" competence. International Journal of Science and Mathematics Education, 13(2), 369-387.

Lamberg, T., \& Wiest, L. R. (2015). Dividing fractions using an area model: A look at in- service teachers' understanding. Mathematics Teacher Education and Development, 17(1), 30-43.

Lawson, T., Cakmak, M., Günduz, M., \& Busher, H. (2015). Research on teaching practicum- A systematic review. European Journal of Teacher Education, 38(3), 392-407.

Llinares, S. (2013). Professional noticing: A component of the mathematics teacher's professional practice. SISYPHUS Journal of Education, 1(3), 76-93.

Lu, X., Kaiser, G., \& Leung, F.K.S. (2020). Mentoring Early Career Mathematics Teachers From the Mentees' Perspective - A Case Study From China. International Journal for Science and Mathematics Education, 18, 1355-1374.

Mason, J. (2002). Researching your own practice: The discipline of noticing. Routledge Falmer.

National Council of Teachers of Mathematics [NCTM] (2000). Principles and standards for school mathematics. Reston, VA: National Council of Teachers of Mathematics.

Nickerson, S. D., Lamb, L., \& LaRochelle, R. (2017). Challenges in measuring secondary mathematics teachers' professional noticing of students' mathematical thinking. In E. Schack, M. Fisher, \& J. Wilhelm (Eds.), Teacher noticing: Bridging and broadening perspectives, contexts, and frameworks (pp. 381-398). Springer.

Perlwitz, M. D. (2005). Dividing fractions: Reconciling self-generated solutions with algorithmic answers. Virginia Mathematics Teacher, 37(2), 25-28.

Petit, M. M., Laird, R., \& Marsden, E. (2010). Informing practice: They "get" fractions as pies; now what? Mathematics Teaching in the Middle School, 16(1), 5-10.

Roth McDuffie, A., Foote, M. Q., Bolson, C., Turner, E. E., Aguirre, J. M., Bartell, T. G., Drake, C., \& Land, T. (2014). Using video analysis to support prospective K-8 teachers' noticing of students' multiple mathematical knowledge bases. Journal of Mathematics Teacher Education, 17, 245-270.

Sánchez-Matamoros, G., Fernández, C., \& Llinares, S. (2015) Developing pre-service teachers' noticing of students' understanding of the derivative concept. International Journal of Science and Mathematics Education, 13, 1305-1329.

Santagata, R., König, J., Scheiner, T., Nguyen, H., Adleff, A.-K., Yang, X., \& Kaiser, G. (2021). Mathematics teacher learning to notice: a systematic review of studies of video-based programs. ZDM Mathematics Education, 53(1), 119-134.

Sherin, M. G., Jacobs, V., \& Philipp, R. (Eds.). (2011). Mathematics teacher noticing: Seeing through teachers' eyes. Routledge.

Sherin, M. G., Russ, R. S., \& Colestock, A. A. (2011). Accessing mathematics teachers' in-the-moment noticing. In M. G. Sherin, V. R. Jacobs, \& R. A. Philipp (Eds.), Mathematics teacher noticing: Seeing through teachers' eyes (pp. 79-93). New York: Routledge. 
Sherin, M. G., \& van Es, E. A. (2009). Effects of video club participation on teachers professional vision. Journal of Teacher Education, 60(1), 20-37.

Simsek, Z. Z. (2020). Pre-service middle grade mathematics teachers' ability to notice: The case of fractions. Başkent University Journal of Education, 7(2), 250-266.

Star, J. R., Lynch, K. H., \& Perova, N. (2011). Using video to improve mathematics' teachers' abilities to attend to classroom features: A replication study. In M. G. Sherin, V. R. Jacobs, \& R. A. Philipp (Eds.), Mathematics teacher noticing: Seeing through teachers' eyes (pp. 117-133). Routledge.

Star, J. R., \& Strickland, S. K. (2008). Learning to observe: Using video to improve preservice mathematics teachers' ability to notice. Journal of Mathematics Teacher Education, 11(2), 107-125.

Stockero, S. L., Leatham, K. R., Van Zoest, L. R., \& Peterson, B. E. (2017a). Noticing distinctions among and within instances of student mathematical thinking. In E. O. Schack, M. H. Fisher, \& J. A. Wilhelm (Eds.), Teacher noticing: Bridging and broadening perspectives, contexts, and frameworks (pp. 467-480). Springer.

Stockero, S. L., Rupnow, R. L., \& Pascoe, A. E. (2017b). Learning to notice important student mathematical thinking in complex classroom interactions. Teaching and Teacher Education, 63, 384-395.

Tirosh, D. (2000). Enhancing prospective teachers' knowledge of children's conceptions: The case of division of fractions. Journal for Research in Mathematics Education, 31(1), 5-25.

Unlu, M., \& Ertekin, E. (2012). Why do pre-service teachers pose multiplication problems instead of division problems in fractions? Procedia-Social and Behavioral Sciences, 46, 490-494.

Van Es, E. A. (2011). A framework for learning to notice student thinking. In M. G. Sherin, V. R. Jacobs, \& R. A. Philipp (Eds.), Mathematics teacher noticing: Seeing through teachers' eyes (pp. 134-151). Routledge.

Yin, R. K. (2003). Case study research: Design and methods. SAGE.

Zembat, İÖ. (2015). An alternative route to teaching fraction division: Abstraction of common denominator algorithm. International Electronic Journal of Elementary Education, 7(3), 399-422.

\section{Authors and Affiliations}

\section{Reyhan Tekin-Sitrava $^{1}$ (D) $\cdot$ Gabriele Kaiser $^{2,3}$ (D) $\cdot$ Mine Işıksal-Bostan $^{4}$ (D)}

\section{Reyhan Tekin-Sitrava}

reyhan_tekin@yahoo.com

Mine Işıksal-Bostan

misiksal@metu.edu.tr

1 Faculty of Education, Kırıkkale University, Kırıkkale, Turkey

2 Faculty of Education, Universität Hamburg, Von-Melle-Park 8, 20146 Hamburg, Germany

3 Institute for Teacher Education and Learning Sciences, Australian Catholic University, Brisbane, Australia

4 Faculty of Education, Middle East Technical University, Ankara, Turkey 